\title{
219 Friction Control and Flying Height Adjustment of Head Sliders with Piezoelectric Micro-actuator \\ (マイクロ圧電アクチュエータによる磁気ヘッドスライダ摩擦制御および浮上量調整)
}

\author{
○学 蘇 立志 (東北大) 正栗田 昌幸 徐 鈞国（日立機械研） \\ 正 加藤 康司（東北大） \\ Lizhi SU, Tohoku University, Aramaki-Aza-Aoba 01, Sendai, Miyagi \\ Masayuki KURITA, Junguo XU, Mechanical Engineering Research Laboratory, Hitachi, Ltd \\ Koji KATO, Tohoku University
}

\section{Introduction}

The remarkable increase in the recording density in recent years was mainly obtained by the miniaturization of the slider, and reduction in the flying height of the head. Ever increasing recording densities require that a slider in a hard disk drive must have an ultra-low flying height. A flying height under $10 \mathrm{~nm}$ is required to achieve over 100 Gbits/in ${ }^{2}$ in recording density [1]. It is obvious that at such a low flying height, deviation in flying height of individual sliders due to manufacturing tolerances will become a big issue. An active-head slider, which allows the flying height to be adjusted individually and the manufacturing tolerances to be compensated, has been developed. While adjusting the flying height of the active-head slider closer towards the disk surface it is very likely that the slider will contact the disk surface [2,3]. Furthermore, since an atomic-level smooth disk is necessary for such a low flying height, head-disk contact may cause large friction and increase the risk of a head crash. To improve the reliability of the head disk interface, it is not sufficient to avoid contact or head crash only by ways of lifting the actuator head. In response to the above-mentioned issues, we have developed a novel method that enables an active-head slider to approach a disk surface safely, namely, tapping (micro-vibration) the head to reduce the friction when the slider contacts the disk [4].

In this paper, both friction control and flying height adjustment will be demonstrated by means of Dynamic Flying Height Tester.

\section{Experiments}

Figure 1 shows the schematic of an active-head slider, which contains four non-active pads and one active-pad. The slider is supported by hydrodynamic force generated at four non-active pads. Generally, non-active pads are called an inner leading pad, an outer leading pad, an inner trailing pad and an outer trailing pad, according to the air bearing geometry related to the disk surface. Moreover, the active-pad, where magneto-resistive sensor is located, is also called a central trailing pad. Flying heights were measured at the central trailing pad (active pad), and two non-active pads (inner trailing pad and outer trailing pad).

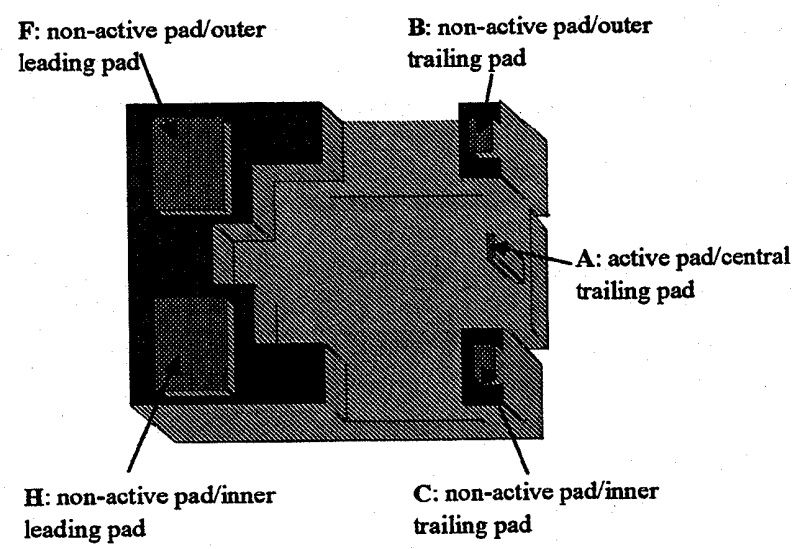

Figure 1 The schematic of an active-head slider that contains four non-active pads and one active-pad

The active-head slider flies over the disk surface at the diameter of $29 \mathrm{~mm}$ without any skew. The disk velocity is $4200 \mathrm{rpm}$. The disk surface with the surface roughness of $0.6 \mathrm{~nm}$ was used in our test.

\section{Experimental results}

\subsection{Flying height adjustment}

Figure 2 shows the flying height as a function of drive voltage at three points (A: active-pad/central trailing pad; B: outer trailing pad; C: inner trailing pad). It must be noted here that the drive voltage is a DC voltage, but not an $\mathrm{AC}$ voltage. It is clear that the flying height of the central trailing pad decreases with increasing drive voltage, while the flying height of the outer trailing pad remains almost 
constant with increasing drive voltage. When the drive voltage is zero, the flying height of the central trailing pad is $24 \mathrm{~nm}$, which matches with the specific value. And the flying height decreases from 24 to $10 \mathrm{~nm}$ under a drive voltage of $10 \mathrm{~V}$. However, the flying height of the non-active pad increases 2 or $3 \mathrm{~nm}$ under a drive voltage of $10 \mathrm{~V}$. It is considerably smaller compared with the decrease in flying height of an active-pad. This suggests that flying height can be adjusted uniformly. The slider is almost entirely supported by air film pressure generated at the air bearing pads. And flying height is controlled by the deflection of an actuator portion.

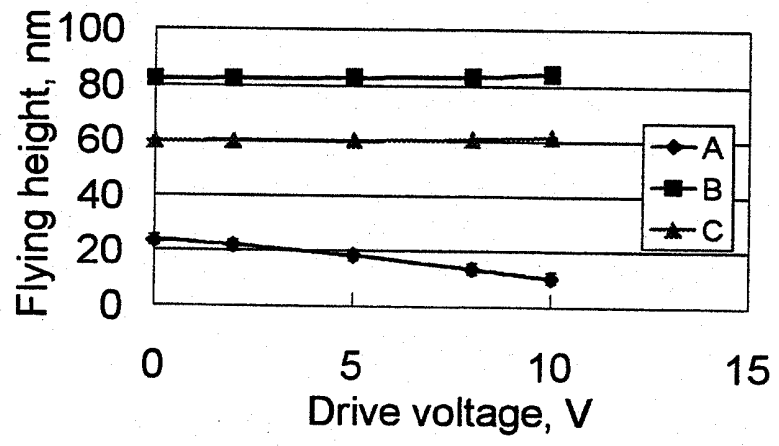

Figure 2 Flying height and drive voltage, the speed is 4200 $\mathrm{rpm}$ and the slider is positioned at a disk radius of $29 \mathrm{~mm}$.

\subsection{Friction control}

Figure 3 shows the flying height at the active-pad (A) with and without vibration as a function of velocity on the glass disk surface with a surface roughness of 0.6 $\mathrm{nm}$. The vibration is $250 \mathrm{kHz}$ sine waveform with an amplitude of $260 \mathrm{~nm}$ measured when the active-head slider does not fly over disk surface. In the case of without vibration, the flying height initially increases, which maybe due to the air film lift up. When the head approaches the disk surface, air film is compressed. This compressed air film prevents the head further approaching to disk surface. Flying height reaches maximum $(28 \mathrm{~nm})$ at the velocity of $4200 \mathrm{rpm}$. This value matches with the specific value mentioned in the design description. Then the flying height achieves the minimum (15 nm) and increases significantly. It is noted that fluctuation of flying height indicates the contact between the slider and the disk surface. The amplitude of fluctuation is not significantly large because of the high pitch stiffness of the slider. In the case of with vibration, flying height remains almost constant when the velocity decreases. It is therefore indicated that vibration could alleviate the fluctuation of flying height after contact. Flying height fluctuation is caused by the high friction and high friction variance after contact. Therefore, friction control by vibration is useful for applications in hard disk drives.

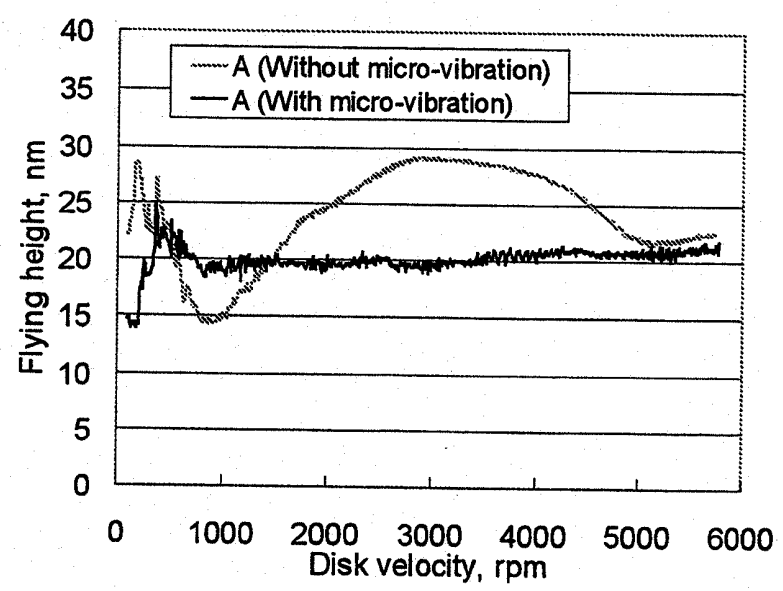

Figure 3 Flying height at the active-pad (A) with and without vibration as a function of velocity on the glass disk with roughness $(\mathrm{Ra})$ of $0.6 \mathrm{~nm}$.

\section{Conclusions}

The results show that flying height could be reduced and decreases from 24 to $10 \mathrm{~nm}$ by applying $10 \mathrm{~V}$ to the actuator. It is indicated that micro-vibration is effective in avoiding a high friction force and a head crash when an active-pad in contact with the smooth disk surface during flying height adjustment.

\section{References}

[1] A.K. Menon, Interface tribology for $100 \mathrm{~Gb} / \mathrm{in}^{2}$, Tribology International, Vol.33, 2000, pp.299-308.

[2] H. Kohira, H. Tanaka, H. Tokisue and M. Matsumoto, Friction force of negative pressure sliders for proximity recording. IEEE Transactions on Magnetics, Vol.33, No.5, 1997, pp.3157-3159.

[3] H. Tanaka, S. Yonemura and H Tokisue, Slider dynamics during continuous contact with textured and smooth disks in ultra low flying height, Digest of APMRC, 2000, TB3.

[4] L.Z. Su, J. Xu, M. Kurita, K. Kato and K. Adachi, Tapping effect on friction between slider and disk, Abstract of the $2^{\text {nd }}$ International Workshop on Microtribology, Ishigaki Island, Japan, 2002. 